\title{
Minimally Invasive Surfactant Therapy: New Age
}

Francisco José Canals Candela*, Carolina Vizcaíno Díaz, María Jesús Ferrández Berenguer, María Isabel Serrano Robles, Consuelo Vázquez Gomis and José Luís Quiles Durá

Section of Neonatology, Department of Pediatrics, Hospital General Universitario de Elche, Elche, Alicante, Spain

\begin{abstract}
For many years preterm infants with respiratory distress syndrome (RDS) have been managed with intubation and surfactant administration, but advances in Neonatology have allowed a softer therapy in newborns. The use of non-invasive respiratory support has been widespread. This has implied that surfactant administration, linked to mechanical ventilation, is just used in cases of non-invasive respiratory support failure. Nowadays Minimally Invasive Surfactant Therapy (MIST) allows neonatologists to use surfactant administration with non-invasive respiratory support. MIST techniques by tracheal catheterization have shown good results reducing the need of mechanical ventilation, bronchopulmonary dysplasia and improved oxygenation. These techniques are safe, effective, gentle and feasible to perform in all level NICUs.
\end{abstract}

Keywords: Surfactant; MIST; Distress respiratory syndrome; Newborn

\section{The Beginning}

Dr. Von Neergaard first detected the surface tension in the gasliquid interphase and its role in the lung compliance in 1929, showing that more pressure was required to inflate lungs with air than with aqueous solution like water and concluding that retractile force of the lung was dependent on the surface tension in the alveoli [1]. To date, great advances in this field have been done. In 1959, Dr. Avery stablished the causal relationship between the hyaline membrane diseases in the premature infant with the absence of a substance that decreased the surface tension and so, increased the lung volume [2].

After these discoveries, research study was headed for finding a way to create that foamy mix of proteins and fats called surfactant, but it was not until twenty years later, in 1980, when Dr. Fujiwara published the first clinical experience with exogenous surfactant, showing an improvement in oxygenation [3]. Ten years later the FDA approved the clinical use of this substance and contributed to the stunning advances in the prognosis of the premature infants with RDS, reducing air leak, oxygenation and neonatal death [4].

\section{Type and Dose}

Different surfactant preparations have been licensed for the treatment of the RDS in the premature newborn and natural ones lead to better findings than synthetic preparations. In turn, the discussion between bovine vs. porcine surfactants has shown better results with the porcine ones (poractant alpha) at the dose of $200 \mathrm{mg} / \mathrm{kg}$, reducing deaths [RR 0.51 (CI 95\% 0.30-0.89)] and the need for redosing [RR 0.71 (CI 95\% 0.57-0.88)] [4,5].

The optimum moment to instill the surfactant has been also widely discussed and better outcomes are obtained in the prophylactic and in early administration in contrast with the rescue one, reducing mortality [RR 0.84 (CI 95\% 0.74-0.95)] and respiratory morbidity [RR 0.69 (CI $95 \% 0.55-0.86)][6,7]$.

Nowadays trend about the management of neonatal RDS in the premature infant can be summarized in one main idea: the softer the management is, the better. With this concept in mind a new goal comes into view: avoiding intubation. This is the reason why the non-invasive respiratory support tries to become a substitute to intubation and mechanical ventilation when it is possible. This modality has shown a reduction in intubation, surfactant administration and non-significant reduction of death or bronchopulmonary dysplasia [RR 0.80 (CI 95\% 0.58-1.12)] [8]. When comparing intubation and surfactant administration to non-invasive respiratory support, the latest is a valid alternative [9].

On the other hand, newborns managed with non-invasive respiratory support, may need intubation and surfactant administration in a later phase of their evolution, and consequently, they cannot take advantage from the early surfactant therapy. This failure has been studied and estimated in $22 \%$ in the premature infants managed initially with this non-invasive support [10].

\section{Early Surfactant and Early Non-Invasive Respiratory Support}

Both early surfactant and non-invasive respiratory support have shown benefits, so the next question should be which one is the best option. In this new age of softer management of preterm infants the question should turned into: why not using both?

The option of giving surfactant reducing mechanical ventilation as much as possible is the INSURE technique (INtubate- SURfactantExtubate). This method consists in intubation to instill exogenous surfactant and after that, extubation and connecting the patient to a non-invasive respiratory support. A reduction in mechanical ventilation needs has been shown in previous studies [11,12].

Some disadvantages about the INSURE method can be stated as follows: we are not completely avoiding intubation or mechanical ventilation, although they are used for a shorter time than in the classical method. In addition, there are patients in which we will not be able to extubate after the intubation. And, finally, we will not avoid to ventilate with positive pressure peaks through the endotracheal tube

*Corresponding author: Francisco José Canals Candela, Department of Pediatrics, Hospital General Universitario de Elche, Elche, Alicante, Spain, Tel: +34699002619; E-mail: canals.candela@gmail.com

Received June 26, 2015; Accepted July 09, 2015; Published July 18, 2015

Citation: Canals FJ, Vizcaíno C, Ferrández MJ, Serrano MI, Vázquez C, Quiles JL, et al. (2015) Minimally Invasive Surfactant Therapy: New Age. J Neonatal Biol 4: 182. doi:10.4172/2167-0897.1000182

Copyright: (C) 2015 Candela FJC, et al. This is an open-access article distributed under the terms of the Creative Commons Attribution License, which permits unrestricted use, distribution, and reproduction in any medium, provided the original author and source are credited. 
during intubation. This positive pressure trough the tube has been demonstrated being more harmful than non-invasive ventilation [13].

Moving on, next step was to avoid completely the intubation, and this is how minimal invasive surfactant therapy appeared, receiving the name of MIST techniques (Minimally Invasive Surfactant Therapy). In this category we can find techniques like nasopharyngeal instillation, laryngeal mask or aerosolization, but none of these methods have demonstrated to be efficient enough to become a wide spread technique [14].

The most used method in MIST therapy is the tracheal catheterization like the Cologne method, described by Dr. Kribs, in which a feeding tube of 4-5 FG is used to introduce the surfactant. Its inconvenient is the need of Magill's forceps used to introduce a feeding tube through the vocal cords. Reduction of mechanical ventilation has been reported related to the Cologne method. A strong alternative to the Cologne method is the Hobart method, developed by Dr. Dargaville. In this procedure an angiocatheter is used to instillate the surfactant. This catheter is stiffer than the feeding tube, being easier to guide it through the vocal cords under direct vision without using Magill's forceps [15-18]. The surfactant administration during a noninvasive respiratory support is associated with a better distribution of the surfactant, as shown in animal models [19].

MIST techniques have shown better results than INSURE method reducing bronchopulmonary dysplasia and the needs of mechanical ventilation [20].

\section{Not Only for High Level NICUs}

Is this modern management of the neonatal RDS only feasible in high level NICUs in hospitals with huge resources? Not in our opinion. In medium level NICUs, like ours, located in the south-east of Spain, MIST has been included in the general practice. Surfactant is administered by MIST using Hobart method in premature infants. In these newborns a lack of surfactant is suspected and do not need to be intubated in the initial stabilization, being managed with non-invasive ventilation.

Intubation criteria are the standard in clinical practice. Premature newborns are intubated whenever there are contraindications for noninvasive ventilation or when this last fails, that is, if there is a persistent need of $\mathrm{FiO}_{2} \geq 0.3$ (despite surfactant administration), and/or persistent respiratory acidosis or apnea.

Few incidences have been registered since the MIST technique is performed in our hospital and the results show us that newborns managed with MIST technique are good, with a remarkable reduction of intubations in the first 72 hours of life. This procedure has proven to be easy to perform by pediatricians with experience in orotracheal intubation.

The retrospective results collected by our group in the first two years since the introduction of MIST technique in our NICU will be published soon in Anales de Pediatría [21].

\section{Conclusions}

Management of the neonatal RDS has experienced huge improvements in recent years. In the age of neonatal softer management, minimal invasive surfactant therapy is perhaps the best treatment we can give in premature infants with RDS if there is no need of intubation.

Minimal invasive surfactant therapy is a safe and effective technique that allows to separate the surfactant administration and the mechanical ventilation, which were a sole treatment until a few years ago. MIST procedure can be performed easily in hospitals with NICUs regardless of their level.

\section{References}

1. Obladen M (2005) History of surfactant up to 1980. Biol Neonate 87: 308-316.

2. Avery ME, Mead J (1959) Surface properties in relation to atelectasis and hyaline membrane disease. Am J Dis Child 97: 517-523.

3. Fujiwara T, Maeta H, Chida S, Morita T, Watabe Y, et al. (1980) Artificia surfactant therapy in hyaline-membrane disease. Lancet 8159:55-59.

4. Sweet D, Carnielli V, Greisen G, Hallman M, Ozek E, et al. (2013) European Consensus Guidelines on the Management of Neonatal Respiratory Distress Syndrome in Preterm Infants-2013 Update. Neonatology 103: 353-368.

5. Singh N, Hawley KL, Viswanathan K (2011) Efficacy of porcine versus bovine surfactants for preterm newborns with respiratory distress syndrome: systematic review and meta-analysis. Pediatrics 6: e1588-1595.

6. Yost CC, Soll RF (1999) Early versus delayed selective surfactant treatment for neonatal respiratory distress syndrome. Cochrane Database Syst Rev 4 CD001456.

7. Soll RF, Morley CJ (2001) Prophylactic versus selective use of surfactant in preventing morbidity and mortality in preterm infants. Cochrane Database Syst Rev 2CD000510.

8. Morley CJ, Davis PG, Doyle LW, Brion LP, Hascoet JM, et al. (2008) Nasal CPAP or intubation at birth for very preterm infants. N Engl J Med 358: 700-708.

9. SUPPORT Study Group of the Eunice Kennedy Shriver NICHD Neonatal Research Network,Finer NN, Waldemar A, Carlo WA, Walsh MC, et al. (2010) Early CPAP versus Surfactant in Extremely Preterm Infants. N Engl J Med 21 1970-1979.

10. Dargaville P, Aiyappan A, De Paoli AG, Dalton RG, Kuschel CA et al. (2013) Continuous Positive Airway Pressure Failure in Preterm Infants: Incidence Predictors and consequences. Neonatology 104: 8-14.

11. Bohlin K, Gudmundsdottir T, Katz-Salamon M, Jonsson B, Blennow M (2007) Implementation of surfactant treatment during continuous positive airway pressure. Journal of Perinatology 27: 422-427

12. Dunn S, Kaempf J, De Klerk A, et al. (2011) Randomized Trial Comparing 3 Approaches to the Initial Respiratory Management of Preterm Neonates. Pediatrics 128: e1069-77

13. Nilsson R, Grossmann G, Robertson B (1980) Bronchiolar epithelial lesions induced in the remature rabbit neonate by short periods of artificial ventilation. Acta Pathol Microbiol Scand A 6: 359 -367.

14. Dargaville PA (2012) Innovation in Surfactant Therapy I: Surfactant Lavage and Surfactant administration by Fluid Bolus Using Minimally Invasive Techniques. Neonatology 101: 326-336

15. Kribs A, Pillekamp F, Hünseler C, Vierzig A, Roth B (2007) Early administration of surfactant in spontaneous breathing with nCPAP: Feasibility and outcome in extremely premature infants (postmenstrual age $<=27$ weeks). Paediatr Anaesth 17: 364-369.

16. Dargaville PA, Aiyappan A, De Paoli AG, Kuschel CA Kamlin COF, et al. (2013) Minimally-invasive surfactant therapy in preterm infants on continuous positive airway pressure. Arch Dis Child Fetal Neonatal Ed 98: F122-126.

17. Kribs A, Zielger A, Laux R, Gopel W, Andreas, et al. (2011) Avoidance of mechanical ventilation by surfactant treatment of spontaneously breathing preterm infants (AMV): an open-label, randomised, controlled trial. Lancet 378: 1627-1634.

18. Aguar M, Vento M, Dargaville PA (2014) Minimally invasive surfactant therapy: An update. Neo Reviews 15: e275-276.

19. Bohlin K, Bouhafs RK, Jarstrand C, Curstedt T, Blennow M, et al. (2005) Spontaneous Breathing or Mechanical Ventilation Alters Lung Compliance and Tissue Association of Exogenous Surfactant in Preterm Newborn Rabbits. Pediatr Res 57: 624-630

20. Kanmaz HG, Erdeve O, Canpolat FE, Mutlu B, Dilmen U (2013) Surfactant administration via thin catheter during spontaneous breathing: Randomized controlled trial. Pediatrics 131: e502-509.

21. Canals-Candela FJ, Vizcaíno-Díaz C, Ferrández-Berenguer MJ (2015) Terapia con surfactante con técnica mínimamente invasiva: experiencia en un hospital terciario. An Pediatr (Barc). Article in press. 